\title{
STUDY ON MODIFICATION FOR PAINLESS INGUINAL HERNIA REPAIR
}

\author{
Siladri Sengupta ${ }^{1}$, Banyeswar Pal', Hem Narayan $\mathrm{Jha}^{3}$
}

${ }^{1}$ Associate Professor, Unit Head-Unit II, Department of Surgery, ESIC-PGIHSR, ESIC Medical College and ESIC Hospital.

${ }^{2}$ Assistant Professor, Unit-II, Department of Surgery, ESIC-PGIHSR, ESIC Medical College and ESIC Hospital.

3Junior Resident, Unit-II, Department of Surgery, ESIC-PGIHSR, ESIC Medical College and ESIC Hospital.

\section{ABSTRACT}

\section{BACKGROUND}

It is a retrospective study.

Aim of this study is to minimise the postoperative pain and increase early mobility of the patient to resume their early normal $\mathrm{d}$ ay-to-day work.

\section{MATERIALS AND METHODS}

Study included 50 patients of which 25 underwent the modified surgery as invagination of sac with ilioinguinal nerve neurectomy a nd Mesh repair, whereas the other 25 patients underwent conventional excision of sac and mesh repair.

\section{DISCUSSION}

Chronic pain is the most debilitating complication after inguinal hernia repair which affects patient's satisfaction and quality of life. It is found in this study that the patients who underwent modified painless hernia surgery with sac invagination along with neurect omy and Mesh repair have significant painless post-operative period and early mobility for normal work.

\section{RESULTS}

In this study out of 50 patients, the patients who underwent neurectomy with sac invagination did not develop significant pain during 6 months postoperative period in contrast to those who underwent only mesh repair with sac excision.

\section{CONCLUSION}

As this study is in a small scale; however, a large scale study adopting this procedure in a multi-region study can consolidate the present findings.

\section{KEYWORDS}

Inguinal Hernia, Postoperative Pain, Mesh Repair, Neurectomy, Invagination of Sac.

HOW TO CITE THIS ARTICLE: Sengupta S, Pal B, Jha HN.Study on modification for painless inguinal hernia repair. J. Evolution Med. Dent. Sci. 2016;5(94):6959-6961, DOI: 10.14260/Jemds/2016/1574

\section{BACKGROUND}

Inguinal hernias account for $75 \%$ of all abdominal wall hernias, and with a lifetime risk of $27 \%$ in men and $3 \%$ in women. Repair of these hernias is one of the most commonly performed surgical procedures in the world. $[1,2]$

Although the laparoscopic repair of inguinal hernias have advantages.[3,4,5,6,7] like reduced postoperative pain, diminished requirement for narcotics, earlier return to work over the conventional open repair i.e. the open, mesh-based, tension-free repair remains the criterion standard, specially where the hands of adequately trained surgeons are lacking. But in such an open method chronic post-operative pain and quick mobility for work are the major health concern.

The present study is contemplated to increase the quality of life in regard to post-operative pain even by this open surgical method.

Financial or Other, Competing Interest: None.

Submission 18-10-2016, Peer Review 11-11-2016,

Acceptance 17-11-2016, Published 24-11-2016.

Corresponding Author:

Dr. Siladri Sengupta,

Flat No. 13C1, Bay Tower,

Hiland Park-1925, Chak Garia (P.O),

Chak Garia, Kolkata-700094,

West Bengal.

E-mail: siladrisen2@gmail.com

DOI: $10.14260 /$ jemds $/ 2016 / 1574$

\section{(c) (i) $\$$}

\section{MATERIALS AND METHODS}

This is a retrospective study done in the Unit -II of Dept. of Surgery at ESIC Medical College, Joka, Kolkata, West Bengal, India from September 2015 to February 2016. All cases of Painless Inguinal Hernia presented in the SOPD of Unit -II were included in the study. date, sex, age, clinical presentation, related history (Unilateral or Bilateral) were noted. The age of the diagnosed patient varies from 20 yrs. to $70 \mathrm{yrs}$. with mean age of presentation at $46 \mathrm{yrs}$. Only Male Patients were included in this study. The study comprises of 50 patients submitted to inguinal hernia surgery with open technique under regional anaesthesia. Inclusion criteria were painless inguinal hernia and exclusion criteria were previous surgery/recurrence, pain over hernia, and incarcerated hernias.

Out of 50 cases of inguinal hernia in 6 months' duration, all of them underwent surgery. Out of these, 25 patients underwent Tension Free Mesh Repair along with Modification like Inguinal neurectomy, and invagination of hernia sac in indirect \& direct Hernias (as retrieved from Operation Note) are considered as Test group and remaining 25 patients from the inclusion group underwent only tension free mesh repair with sac excision without neurectomy or sac Invagination are labelled as control group for this study and the results are compared. In the post-operative period, 8 patients had wound infection treated conservatively with antibiotics and 4 patients developed scrotal oedema treated with antibiotics and scrotal support. Patients were followed up for 6 months. The 
informed written consent was accepted from all of the patients or their responsible relative and the study design was approved by ethical clearance committee of the institute. For grading of pain sensation perceived by the patient who underwent surgical procedure the numerical pain rating scale (NRS-11) was used and as per this scale 0-3 is considered as Mild, 4-6 as moderate and 7-10 as severe.

Statistical analysis wherever applicable was done using statistical SPSS version 12. Student's T test was done in between control and test group (sample size experiencing different degree of pain sensation as per NRS scale) to determine the significance level and $\mathrm{P}<0.05$ is considered as statistically significant.

\section{RESULTS}

In the present study, it was found that out of 50 patients, 30 patients $(60 \%)$ had visible hernia on standing and twenty patients $(40 \%)$ had palpable impulse on cough. It was also found that patients with indirect inguinal hernia is preponderant over direct inguinal hernia (Table-1).

Moreover among the diagnosed (studied) group, the occurrence of right-sided hernia is significantly higher than left-sided inguinal hernia (Fig -1)). Also of the total 50 cases, in 15 cases there were adhesions within the contents of sac and in 35 patients there were no adhesions within the sac.

The present study also indicates that the patients who underwent neurectomy with sac invagination did not develop significant pain during 6 months post-operative period in contrast to those who only underwent mesh repair with excision of sac. Amongst those where modified surgery was not performed, 10 patients develop moderate pain requiring no analgesics and 5 patients had severe pain requiring analgesics. It is further observed that amongst the test group (out of 25 patients), 21 experienced mild pain and 3 experienced moderate pain requiring no analgesic and only 1 suffered from severe pain who required mild analgesics for initial few weeks after the modified surgery.

\begin{tabular}{|c|c|c|c|c|}
\hline & \multicolumn{2}{|c|}{$\begin{array}{c}\text { Direct Inguinal } \\
\text { Hernia }\end{array}$} & \multicolumn{2}{c|}{$\begin{array}{c}\text { Indirect Inguinal } \\
\text { Hernia }\end{array}$} \\
\hline & $\begin{array}{c}\text { Sample } \\
\text { No. }\end{array}$ & $\begin{array}{c}\text { \% of } \\
\text { Occurrence }\end{array}$ & $\begin{array}{c}\text { Sample } \\
\text { No. }\end{array}$ & $\begin{array}{c}\text { \% of } \\
\text { Occurrence }\end{array}$ \\
\hline Male & 20 & 40 & 30 & 60 \\
\hline Total & $\mathbf{2 0}$ & $\mathbf{4 0}$ & $\mathbf{3 0}$ & $\mathbf{6 0}$ \\
\hline \multicolumn{3}{|c|}{ Table 1. Occurrence of Direct and Indirect Inguinal } \\
Hernia \\
\hline
\end{tabular}

\begin{tabular}{|c|c|c|c|c|c|c|}
\hline & \multicolumn{2}{|c|}{$\begin{array}{c}\text { Right } \\
\text { Inguinal } \\
\text { Hernia }\end{array}$} & \multicolumn{2}{|c|}{$\begin{array}{c}\text { Left } \\
\text { Inguinal } \\
\text { Hernia }\end{array}$} & \multicolumn{2}{|c|}{$\begin{array}{c}\text { Bilateral } \\
\text { Inguinal } \\
\text { Hernia }\end{array}$} \\
\hline & $\begin{array}{l}\dot{0} \\
z \\
\frac{0}{\sigma} \\
\bar{\Xi} \\
\tilde{\Xi}\end{array}$ & 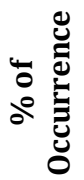 & 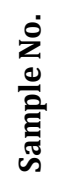 & ¿ & 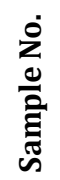 & 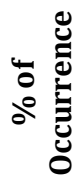 \\
\hline Male & 29 & 58 & 21 & 42 & 4 & 8 \\
\hline Female & NA & NA & NA & $\mathrm{NA}$ & $\mathrm{NA}$ & NA \\
\hline Total & 29 & 58 & 21 & 42 & 4 & 8 \\
\hline
\end{tabular}

\begin{tabular}{|c|c|c|c|c|}
\hline Group & $\begin{array}{c}\text { Total } \\
\text { No. } \\
\text { of } \\
\text { Sample }\end{array}$ & $\begin{array}{c}\text { No. of } \\
\text { Samples - } \\
\text { Mild Pain } \\
\text { (NRS- } \\
11: 0-3)\end{array}$ & $\begin{array}{c}\text { No. of } \\
\text { Samples - } \\
\text { Moderate } \\
\text { Pain (NRS- } \\
\mathbf{1 1 : 4 - 6 )}\end{array}$ & $\begin{array}{c}\text { No. of } \\
\text { Samples - } \\
\text { Severe } \\
\text { Pain (NRS- } \\
11: 7-10)\end{array}$ \\
\hline Control & 25 & 0 & 10 & 5 \\
\hline Test & 25 & 21 & 3 & 1 \\
\hline Table 3. Comparison of Postoperative Complications \\
after Mesh Repair between Test \\
(Neurectomy + Sac Invagination) and Control Group \\
(No Neurectomy + Sac Excision)
\end{tabular}

NRS= Numerical rating scale for pain measurement scale

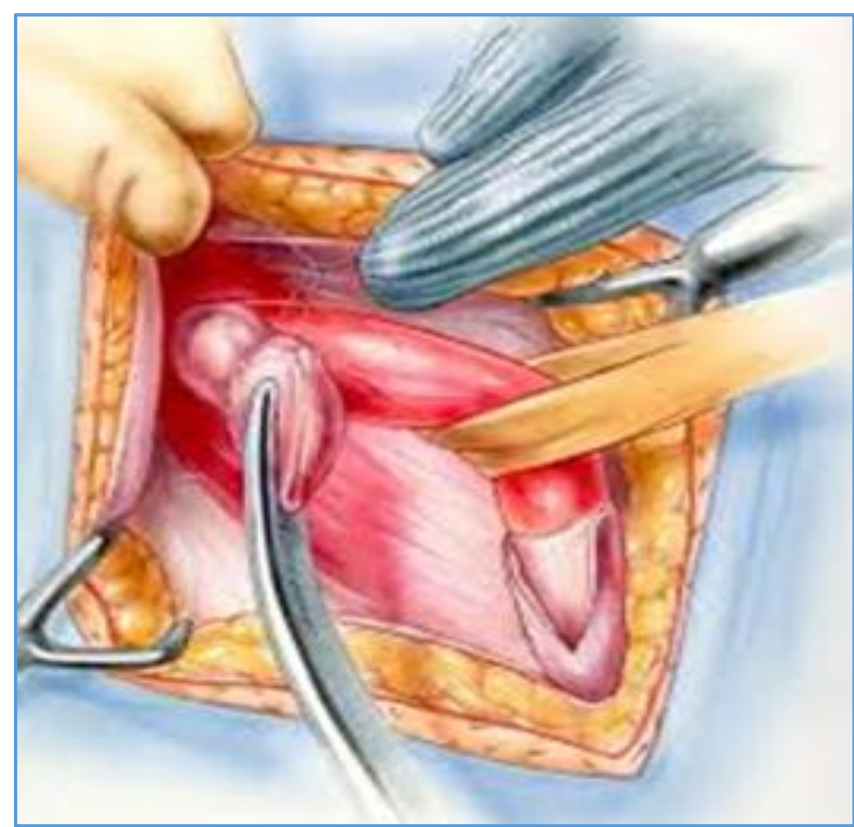

SSC Invagination

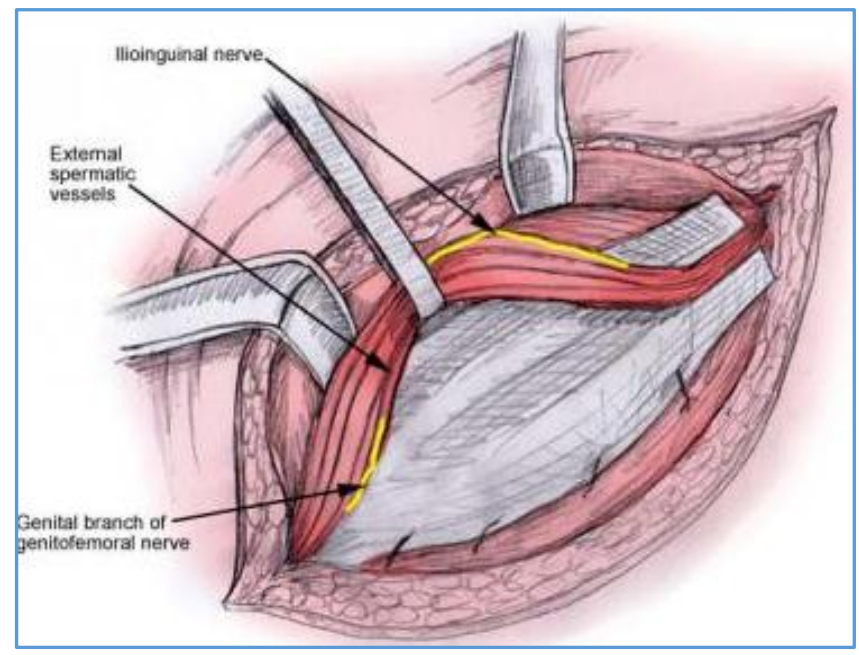

Ilioinguinal Nerve to be Excised 


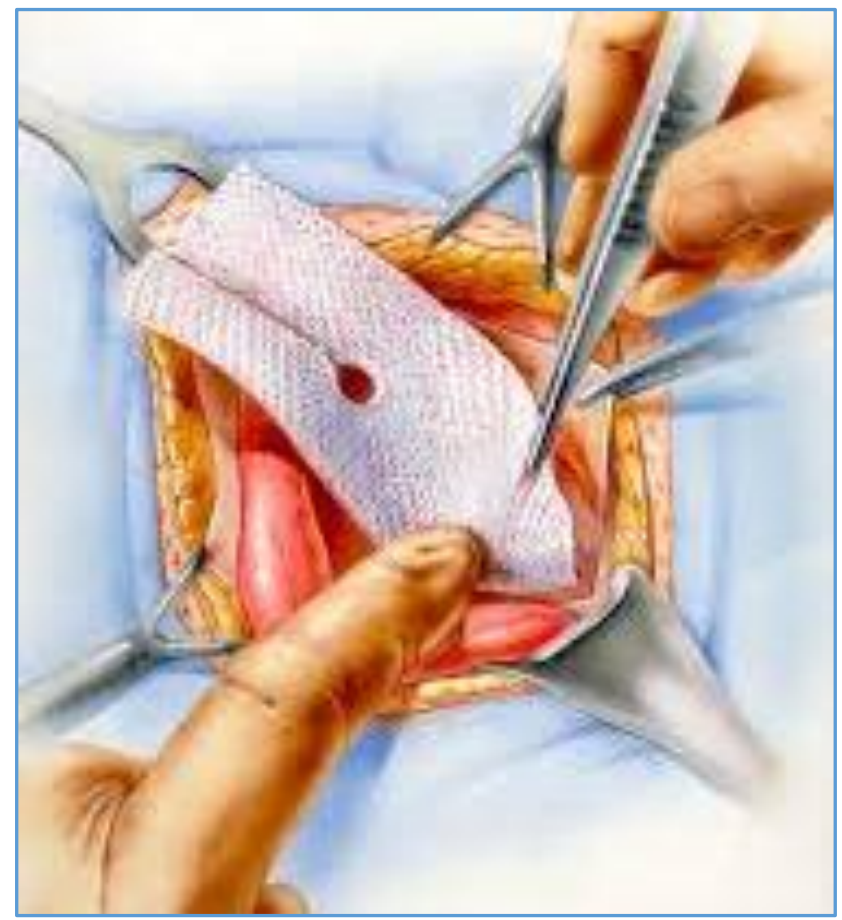

Mesh Implantation

\section{DISCUSSION}

Inguinal hernia is one of the most frequently performed surgeries where most patients have painless inguinal hernia over time. Different studies in different parts of world have shown that inguinal hernia. $[3,4,5,8,9]$ is more common in males. It is also found that the indirect hernia is more common $(\mathrm{P}<)$ than direct hernia. Moreover, the present study indicates the preponderance of right inguinal and left inguinal hernia over the bilateral hernia in this belt as shown by fig 1 . which is in accordance with some other studies.[10,11]

Surgical repair is recommended for medically fit patients with painless inguinal hernia. But in open method, especially the post-operative pain and long immobility are the challenging issues to all surgeons. Chronic groin pain is one of the most debilitating long term complications after inguinal hernia repair which affects patient's satisfaction and quality of life after operation. Recent retrospective studies.[12,13] show the excision of ilioinguinal nerve and invagination of sac without excision wherever feasible along with tension free mesh implantation were associated with lower incidence of chronic groin pain after the operation.

The present study consolidates that abdominal wall repair by mesh repair along with inguinal neurectomy with invagination of sac is highly effective to reduce the groin pain than the patients who underwent the mesh repair with excision of sac without neurectomy as in the group where neurectomy was not performed post-operative groin pain (OMIT) developed within 6 months of post-operative followup in all of the 15 cases.

\section{CONCLUSION}

The present study and its findings thus consolidate the suggestive ways and means to reduce the post-operative pain following tension free mesh repair of inguinal hernia. However, the limitation of this study is the small sample size and limited followup period. So, prospective study on larger scale with larger followup is required to establish the role of prophylactic ilioinguinal neurectomy and invagination of sac instead of excision of sac wherever feasible to improve the quality of life of patients with painless inguinal hernia.

\section{Acknowledgement}

Assistance rendered by technical staff of the dept. is sincerely acknowledged.

\section{REFERENCES}

1. Jenkins JT, O'Dwyer PJ. Inguinal hernias. BMJ 2008;336(7638):269-72.

2. Kuhry E, van Veen RN, Langeveld HR, et al. Open or endoscopic total extraperitoneal inguinal hernia repair? A systematic review. Surg Endosc 2007;21(2):161-6.

3. Kark AE, Kurzer MN, Belsham PA. Three thousand one hundred seventy-five primary inguinal hernia repairs: advantages of ambulatory open mesh repair using local anesthesia. J Am Coll Surg 1998;186(4):447-55.

4. Memon MA, Cooper NJ, Memon B, et al. Meta-analysis of randomized clinical trials comparing open and laparoscopic inguinal hernia repair. $\mathrm{Br} \mathrm{J}$ Surg 2003;90(12):1479-92.

5. McCormack K, Scott NW, Go PM, et al. Laparoscopic techniques versus open techniques for inguinal hernia repair. Cochrane Database Syst Rev 2003;1:CD001785.

6. Novitsky YW, Czerniach DR, Kercher KW, et al. Advantages of laparoscopic transabdominal preperitoneal herniorrhaphy in the evaluation and management of inguinal hernias. Am J Surg 2007;193(4):466-70.

7. Takata MC, Duh QY. Laparoscopic inguinal hernia repair. Surg Clin North Am 2008;88(1):157-78.

8. Fegade S. Laparoscopic versus open repair of inguinal hernia. World J Lap Surg 2008;1(1):41-8.

9. Pancholi M, Sharma P, Patel GR. Retrospective study of repair of inguinal hernia by various methods of surgery, comparing their results and rate of complications in the teaching institute of south Gujarat. Gujarat Medical Journal 2012;67(2):22-4.

10. Abramson JH, Gofin J, Hopp C, et al. The epidemiology of inguinal hernia, a summary in western Jerusalem. J Epidermal Community Health 1978;32(1):59-67.

11. Hokkkan E. The effect of ilioinguinal neurectomy in elective inguinal hernia repair on chronic post-operative pain. Egyptian J Surg 2009;8:156-62.

12. Mui WL, Ng Cs, Fung TM, et al. Prophylactic ilioinguinal neurectomy in open inguinal hernia repair: A double-blind randomized controlled trial. Ann Surg 2006;244(1):27-33.

13. Dennis R, O'Riordan D. Risk factor for chronic pain after inguinal hernia repair. Ann Roy Coll Surg England 2007;89(3):218-20. 